\title{
Comparison of Changes in Disease-Free and Overall Survival of Resectable Rectal Adenocarcinoma between 2010 and 2015
}

\author{
Justas Žilinskas $^{\mathrm{a}}$ Mantas Jokubauskas $^{\mathrm{a}}$ Giedrè Smailytè $^{\mathrm{b}} \quad$ Irina Gineikienè \\ Algimantas Tamelis ${ }^{a}$ \\ aDepartment of Surgery, Medical Academy, Lithuanian University of Health Sciences (LUHS), Kaunas, Lithuania; \\ b Laboratory of Cancer Epidemiology, National Cancer Institute, Vilnius, Lithuania; 'Department of Radiology, \\ Medical Academy, Lithuanian University of Health Sciences (LUHS), Kaunas, Lithuania
}

\section{Keywords}

Rectal cancer surgery - Neoadjuvant therapy ·

Multidisciplinary approach · Magnetic resonance imaging · Survival

\begin{abstract}
Background: Management of rectal cancer (RC) has undergone many changes in recent decades. A multidisciplinary approach to this complex disease is essential, ensuring highquality diagnostic, treatment, and outcomes. We aimed to compare treatment results of $\mathrm{RC}$ in a single-centre setting between 2010 and 2015. Methods: A retrospective comparative study included patients with newly diagnosed and operated resectable RC. Patients' diagnostic and treatment data were analysed. Postoperative morbidity was measured according to the Clavien-Dindo classification. Survival data were received from the Lithuanian Cancer Registry. Continuous variables were expressed as mean and SD. Student $t$ test and one-way ANOVA were used for parametric data and the Mann-Whitney test for non-parametric. A multivariate logistic regression analysis was used to identify independent factors for increased survival. Association between categorical variables was verified using Pearson $x^{2}$. Results: The study included 179 patients: 80 from 2010 and 99 from 2015. Mean sample age was $67.1 \pm 10.7$ years. There was no significant
\end{abstract}




\section{Introduction}

Colorectal cancer is the most common malignant disease of the gastrointestinal tract and is the third most common malignancy in men $(1,026,215$ cases, $10.9 \%$ of total cancers) and the second in women $(823,303,9.5 \%$ of total cancers) worldwide [1]. Unfortunately, it is still a significant cause of morbidity and mortality worldwide, and the incidence is predicted to increase in both genders $[1,2]$. To make matters worse, this number is growing in economically transitioning Eastern European countries, including Lithuania, where the risk has been historically low [2].

In 2018, an estimated 487,714 men and women will be diagnosed with colorectal cancer; 175,219 of them with rectal cancer (RC) [3]. In countries of the EU, the estimated incidence of $\mathrm{RC}$ is 15.8 cases per 100,000 population, and in Lithuania it is 16.2 cases per 100,000 population.

According to the most recent data, the 5-year survival rate for RC was analogous among the Nordic countries (64-69\%) and among most southern European countries $(61 \%)$, while in the Baltic countries survival was lower, ranging between 50 and 59\% [4]. Survival trends between 2000 and 2014 were generally increasing. In Lithuania, the 5-year survival rate of RC patients has changed from 40.6 to $52.7 \%$ in patients diagnosed with RC [5].

The 5-year overall survival (OS) rate has increased from 55.4 up to $63.4 \%$ in the comparative observational cohort study conducted in the three Lithuanian cancer hospitals in 2005 and 2010 [5]. Preoperative diagnosis and surgical treatment as well as a pathological examination of the specimen, and postoperative course were associated with improved OS in RC patients. Though, accessibility of magnetic resonance imaging (MRI) and radiochemotherapy differs among centres.

Fortunately, the management of RC has undergone many changes in recent decades. Including the colorectal cancer management guidelines which were approved by the Ministry of Health of the Republic of Lithuania in 2012 and revised in 2014 [6]. As a result, a multidisciplinary approach to this complex disease is essential, ensuring high-quality treatment and outcomes [7].

Currently, there are various options for a neoadjuvant treatment (NT) regimen for locally advanced RC [8]. Though surgical resection is the main goal for potentially resectable RC. However, the first therapeutic act decided at the multidisciplinary team (MDT) meetings is crucial $[9,10]$.

The purpose of this study was to compare treatment results of RC in a single-centre setting from 2010 with those from 2015 and identify responsible factors in terms of national future perspectives.
Table 1. General characteristics

\begin{tabular}{lccl}
\hline Variable & 2010 & 2015 & $p$ value \\
\hline Patients, $n$ & 80 & 99 & NA \\
Median ASA (range) & $3(1-4)$ & $3(2-4)$ & 0.692 \\
Mean age, years & $64.4 \pm 9.9$ & $66.8 \pm 11.4$ & 0.674 \\
Emergency setting & $2(2.5 \%)$ & $6(6.1 \%)$ & 0.154 \\
Gender, $n$ & & & \\
$\quad$ Male & $47(58.8 \%)$ & $49(49.5 \%)$ & 0.218 \\
$\quad$ Female & $31(31.2 \%)$ & $50(50.5 \%)$ & \\
Cancer stage & & & \\
I & $12(15 \%)$ & $8(8.1 \%)$ & 0.249 \\
II & $16(20 \%)$ & $21(21.2 \%)$ & \\
III & $45(56.3 \%)$ & $58(58.6 \%)$ & \\
IV & $7(8.8 \%)$ & $12(12.1 \%)$ & \\
Diagnostic workup & & & \\
Colonoscopy + biopsy & $80(100 \%)$ & $99(100 \%)$ & NA \\
Liver ultrasound & $62(77.5 \%)$ & $67(67.7 \%)$ & 0.999 \\
ERUS & $18(22.5 \%)$ & $3(3.0 \%)$ & 0.929 \\
Chest X-ray & $60(75.0 \%)$ & $99(100 \%)$ & 0.816 \\
Abdominal - pelvis CT & $42(52.5 \%)$ & $96(97.0 \%)$ & 0.759 \\
Chest CT & $15(18.6 \%)$ & $67(67.7 \%)$ & $<0.001$ \\
Pelvis MRI & $30(37.5 \%)$ & $77(77.8 \%)$ & $<0.001$ \\
Tumor site from linea dentata & & & \\
$<5$ cm & $8(10 \%)$ & $15(15.2 \%)$ & 0.152 \\
$5-10$ cm & $51(63.7 \%)$ & $42(42.4 \%)$ & \\
$>10$ cm & $21(26.3 \%)$ & $42(42.4 \%)$ & \\
\hline & & & \\
\hline & & &
\end{tabular}

ASA (American Society of Anesthesiologists) - Physical Status Classification System. ERUS, endorectal ultrasound; CT, computed tomography; MRI, magnetic resonance imaging; X-ray, Röntgen rays.

\section{Materials and Methods}

A retrospective comparative study included patients with newly diagnosed RC who received surgery during 2010 and 2015. Palliative operations without resection or transanal endoscopic microsurgery without removing lymph nodes were excluded from the study.

Preoperative investigations were performed by the senior radiologists at the Department of Radiology. Clinical tumour, node, metastasis (TNM) staging system was evaluated according to the guidelines of the 2012 European Society of Gastrointestinal and Abdominal Radiology (ESGAR) consensus meeting [11]. RC surgery was performed by 7 senior abdominal surgeons who specializes in coloproctology. Patients' diagnostic and treatment data were analysed. Postoperative morbidity was registered according to the Clavien-Dindo classification and follow-up data was received from the Lithuanian Cancer Registry $[12,13]$.

Preoperative first-line treatment regimens: 5 weeks of conventional chemoradiotherapy (CRT) $(25 \times 2$ Gy per fraction + two cycles of 5-fluorouracil/leucovorin) with delayed surgery for 6-8 weeks or 5 days of short-term radiotherapy (RT) ( 5 x 5 Gy) with immediate surgery afterwards [8].

The study protocol was approved by the Bioethics Centre of the Lithuanian University of Health Sciences (LUHS) (approval number BEC-MF-790).

Statistical Analysis

Continuous variables were expressed as mean and standard deviation (SD). Student $t$ test and one-way ANOVA were used for 
Fig. 1. RC treatment. Surgery $+\mathrm{CHT}+$ RT - Neoadjuvant Chemoradiotherapy followed by surgery. Surgery + RT - Neoadjuvant radiotherapy followed by surgery. Surgery + CHT - Neoadjuvant chemotherapy followed by surgery. Surgery - Surgery alone without Neoadjuvant treatment.

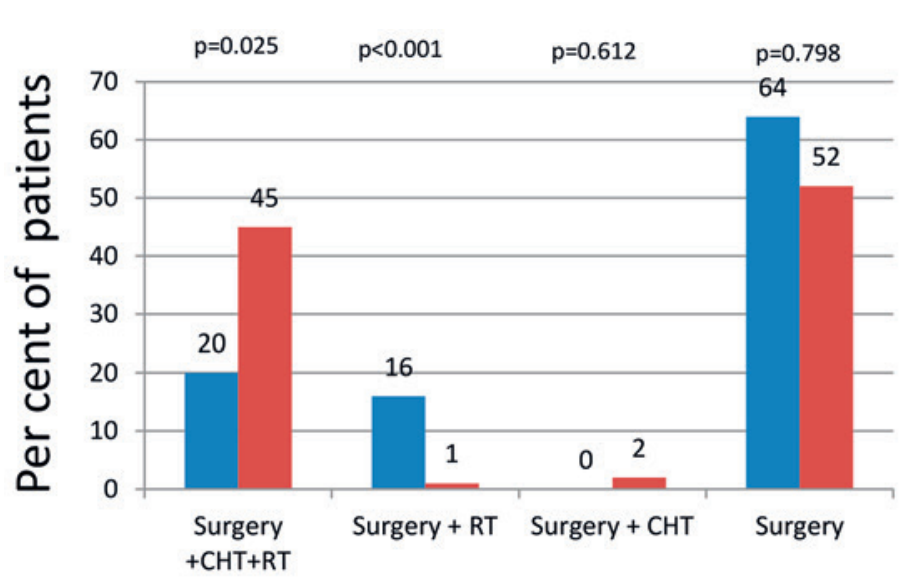

\section{Type of treatment}

parametric data and Mann-Whitney test for non-parametric. The time interval between the date of cancer diagnosis and the date of death or the end of the observation period was defined as the OS of RC patients. A multivariate logistic regression analysis was used to identify independent factors for increased survival. Association between categorical variables was verified using Pearson $\chi^{2}$. The level of significance was set at 0.05 .

\section{Results}

\section{General Information}

A total of 80 patients with a mean age of 67.4 years $(\mathrm{SD}, 9.9)$ were compared with 99 patients with a mean age of 66.8 years (SD, 11.4), who were treated for CRC in 2010 and 2015, respectively. There were 33 (41.2\%) females and 47 (58.8\%) males in 2010. There was a similar gender ratio in 2015, 50 (50.5\%) females and 49 (49.5\%) males. Only 8 patients in total (2.5 and 6.1\%) were on an emergency basis. The median ASA was 3 in both groups. The details of the general characteristics are specified in Table 1. According to our data, the cancer stage did not differ between 2010 and 2015. Unfortunately, there were $5.6 \%$ more patients diagnosed with cancer stages III and IV (65.1 vs. $70.1 \%)$ and $6.9 \%$ fewer patients with cancer stage I in 2015. The distribution of cancer stages is presented in Table 1.

\section{Diagnostic Methods}

Colonoscopy with biopsy and histological examination was performed for all patients (100\%) both in 2010 and 2015. Pelvis MRI and chest CT were performed more often in 2015: the tests increased up to $77.8 \%(p<$ $0.001)$ and $67.7 \%(p<0.001)$, respectively. In addition to this, the circumferential resection margin (CRM) evaluation increased by more than $20 \%(p=0.001)$. There was no significant difference regarding other di-
Table 2. Details on the operative treatment

\begin{tabular}{lccc}
\hline Variable & 2010 & 2015 & $p$ value \\
\hline Operative approach, $n$ & & & \\
$\quad$ Open surgery & $78(97.4 \%)$ & $93(94.0 \%)$ & 0.929 \\
$\quad$ Laparoscopic surgery & $2(2.5 \%)$ & $6(6.0 \%)$ & 0.875 \\
$\quad$ Conversion to open & $1(1.3 \%)$ & $3(3.0 \%)$ & 0.914 \\
Operation method, $n$ & & & \\
TME/anterior rectum & & & \\
$\quad$ resection & $57(71.3 \%)$ & $78(78.8 \%)$ & 0.858 \\
APR & $21(26.3 \%)$ & $18(18.2 \%)$ & 0.743 \\
Proctectomy & $2(2.6 \%)$ & $3(3.0 \%)$ & 0.958 \\
Ostomy, $n$ & & & \\
Ostomy not performed & $14(17.5 \%)$ & $8(8.1 \%)$ & 0.157 \\
Colostomy & $34(42.5 \%)$ & $40(40.4 \%)$ & 0.9 \\
Loop ileostomy & $32(40.0 \%)$ & $51(51.5 \%)$ & 0.929 \\
\hline
\end{tabular}

TME, total mesorectal excision; APR, abdominal perineal resection.

agnostic methods. MRI was performed only for 30 (37.5\%) and endorectal ultrasound (ERUS) for 18 patients $(22.5 \%)$ in 2010. In 2015, ERUS was used for T1 or Tis tumours as an intention for transanal endoscopy instead of a major operation. There were more MRI $(n=77,77.8 \%)$ and less ERUS $(n=3,3 \%)$ performed in 2015. There was no significant difference among low, middle, and high RCs according to tumour site from linea dentata. Middle RCs were the most frequent in 2010 (63.7\%), while middle and high rectal tumours allocated equally (both $42.4 \%$ ) in 2015. Despite the fact that there was a higher number of low RCs in 2015 (10\% in 2010 vs. $15.1 \%$ in 2015 ), we performed more sphincter-preserving operations instead of abdominal perineal resection ( 26.3 vs. $18.2 \%$ ). All diagnostic workup is summarized in Table 1. 
Table 3. Comparison of radiological $\mathrm{T}$ stage before treatment and pathological T stage after treatment

\begin{tabular}{lccc}
\hline & Before treatment & After treatment & \\
\hline 2010 & & & \\
T0 & $0(0 \%)$ & $5(6.8 \%)^{*}$ & $p=0.002$ \\
T1 & $0(0 \%)$ & $20(27.0)$ & \\
T2 & $2(8.7 \%)$ & $41(55.4)$ & \\
T3 & $14(60.9 \%)$ & $5(6.8)$ & \\
T4 & $7(30.4 \%)$ & & \\
\hline 2015 & & $5(5.6)^{*}$ & \\
T0 & $1(1.5)$ & $4(4.4)$ & \\
T1 & $2(3.0)$ & $22(24.4)$ & \\
T2 & $12(17.9)$ & $59(65.6)$ & \\
T3 & $42(62.6)$ & $0(0)$ & \\
T4 & $10(14.9)$ & $p=0.897$ & \\
& $p=0.043$ & & \\
\hline
\end{tabular}

Before treatment means a period before rectal cancer treatment (any of neoadjuvant treatment option followed by surgery or surgery treatment alone) based on clinical pelvic MRI T stage evaluation. After treatment means a period after rectal cancer surgery (including any of neoadjuvant treatment option followed by surgery) based on pathological T stage evaluation.

Table 5. 2-year OS and DFS

\begin{tabular}{|c|c|c|c|c|}
\hline Groups & Surgery $^{\mathrm{a}}$ & Neoadjuvant $^{\mathrm{b}}$ & Total & $p$ value \\
\hline \multicolumn{5}{|c|}{ 2-year OS, $n(\%)$} \\
\hline 2010 & $45(76.7 \%)$ & $15(75 \%)$ & $61(76.3 \%)$ & 0.046 \\
\hline 2015 & $47(83.9 \%)$ & $39(90.7 \%)$ & $86(86.9 \%)$ & \\
\hline \multicolumn{5}{|c|}{ Median DFS, months (range) } \\
\hline 2010 & $27(0-35)$ & $28(3-35)$ & $27(0-35)$ & 0.077 \\
\hline 2015 & $28(0-35)$ & $28(0-34)$ & $28(0-35)$ & \\
\hline
\end{tabular}

${ }^{a}$ The surgery group received no neoadjuvant treatment. ${ }^{b}$ The neoadjuvant group received neoadjuvant treatment followed by surgery. OS, overall survival; DFS, disease-free survival.

\section{Preoperative Treatment}

Neoadjuvant chemoradiotherapy has doubled from $20 \%$ in 2010 to $45 \%$ in 2015 ( $p=0.01)$. Results are shown in Figure 1.

\section{Operative Treatment}

The majority of the operative approach remained open with a slightly increased number of laparoscopies in 2015. The operating approach or method distribution did not differ between groups, conversely, there is a growing tendency of sphincter-preserving operations as well as loop ileostomies. The colostomy rate remained similar to that of 2010 . The operative treatment is presented in Table 2.
Table 4. Postoperative period

\begin{tabular}{lccc}
\hline Variable & 2010 & 2015 & $p$ value \\
\hline Clavien-Dindo classification of & postoperative complications \\
Grade 0 & $69(86.3)$ & $79(79.8)$ & 0.596 \\
Grade I & $4(5.0)$ & $6(6.1)$ & \\
Grade II & $4(5.0)$ & $6(6.1)$ & \\
Grade III a & $0(0)$ & $3(3.0)$ & \\
Grade III b & $2(2.5)$ & $1(1.0)$ & \\
Grade IV a & $0(0)$ & $2(2.0)$ & \\
Grade IV b & $0(0)$ & $2(2.0)$ & \\
Grade V & $1(1.3)$ & $0(0)$ & \\
\hline Length of hospital stay & & & \\
Median hospital stay, range & $10(5-43)$ & $8(5-37)$ & 0.002 \\
Median postoperative hospital & & & \\
$\quad$ stay, range & $8(2-25)$ & $7(4-36)$ & 0.005 \\
\hline
\end{tabular}

\section{Histological Examination}

Comparison of radiological TNM and pathological TNM with one-way ANOVA showed significant difference staging between $2010(p=0.002)$ and $2015(p=$ $0.001)$. The results are summarized in Table 3.

\section{Postoperative Period}

The length of median hospital ( 8 vs. 10 days, $p=0.002$ ) and postoperative stay ( 7 vs. 8 days, $p=0.005$ ) was significantly shorter by 2 and 1 day in 2015, respectively. The distribution of postoperative complications grades according to the Clavien-Dindo classification was not significantly different between 2010 and 2015. However, there were more documented complications in 2015 (13.8 vs. $20.2 \%, p=0.596$ ). Conversely, there was no in-hospital mortality in 2015 compared to one death in 2010. The postoperative period is presented in Table 4.

The 2 -year OS has increased by $10.6 \%(p=0.046)$ and the median disease-free survival (DFS) by $11 \%$. Data are displayed in Table 5. Multivariate logistic regression analysis determined that the availability and performance of MRI were associated with increased OS (OR $=1.529,95 \%$ CI $0.916-2.554, p=0.020$ ).

\section{Discussion/Conclusion}

We found that the 2-year OS rate of resectable RC has significantly increased from $76.3 \%$ in 2010 to $86.9 \%$ in 2015. In Lancet Oncology, an immense population-based national registry study of Denmark, England, Norway, and Sweden has recently been published. For comparison, the 2-year OS was 78.2, 76.2, 80.3, and 79.8\%, respectively [14]. The OS of our study is better due to the exclusion criteria used. Therefore, we observed that pre-treatment staging evaluation and preoperative treatment improved from 2010 to 2015. 
Since the European Union and government-funded Radiological Diagnostic Center (RDC) of LUHS was established in 2012, availability of imaging modality and performance instantly enhanced: pelvis MRI and abdominal CT by 40.3 and $44.5 \%$ in 2015 , respectively. As a consequence, patients waiting times for CT and MRI diagnostic tools had shortened and become a common routine in the examination of RC. Furthermore, our research proposes that clinical staging TNM compared with pathological TNM has improved in terms of quality in 2015.

Conversely, the usage of ERUS has dramatically decreased from 22.5 to $3 \%$ in 2015. In addition, Yimei et al. [15] support this statement, as ERUS has become an alternative only for early-stage RC (Tis, T1-2) due to lack of depth to evaluate other organ invasion, and besides, it is limited by the bulkiness of the tumour.

Pertaining to tumour invasion to organs and structures, thin-cut, high-resolution MRI has become the imaging gold standard to determine treatment options, especially for low RC. Currently, radiologists examine not only $\mathrm{T}$ and $\mathrm{N}$, but also other parameters (e.g., the distance of a tumour to the potential CRM, the presence of a tumour within the extramural rectal vessels [EMVI], discontinuous tumour deposits [N1c], and intersphincteric plane according to the ESGAR consensus meeting) [11, $16]$.

MDT discussions by the LUHS have officially started in 2012 and become a mandatory step for every RC case. In 2015, Prades et al. [17] published a systematic review stating that MDT discussions resulted in better clinical outcomes, with evidence of improved survival among colorectal cancer patients. Intuitively, there appear to be undisputable benefits from MDT in RC, as the first therapeutic act is crucial. However, at the same time, the MDT has to deal with clinical issues when there is no gold standard [18].

Though, the best regimen for preoperative NT has not been established. However, adjuvant chemoradiotherapy has been a standard option for resectable RC until the German Rectal Cancer Study in 2004. Preoperative treatment (CRT or short-course radiotherapy) provides better local control, lower toxicity, and better compliance compared to postoperative treatment [19].

Kairevičè et al. [20] published a randomized controlled trial (RCT) of patients with resectable stage II-III RC stating that the 5-year DFS and OS were significantly better in the preoperative CRT than with delayed surgery in 6-8 weeks or in the preoperative short-course radiotherapy group.

While our study showed more preoperative NT prescribed and better 2-year survival in 2015, a survival benefit was not found until recently. There is a need for more RCTs and meta-analyses to find out the most suitable NT regimen.
On the other hand, we are unable to propose any new study of RC if each institution will not standardize the staging first. The new ESMO guidelines published in 2017 suggest that selection of treatment depends on pelvic MRI locoregional clinical staging (EMVI, T substage, distance to the CRM). As a result, we can expect a better patient selection for the respective preoperative management and to define the extent of surgery [21].

Can we improve in the assessment of nodal status? So far, no uniform criteria exist for defining a node-positive status [22]. Zhang et al. [23] present the chemical shift effect as evaluation criteria for the prediction of lymph node status using MRI imaging with node-for-node matched histopathology. According to their research, the chemical shift effect is predicting the nodal status (border, signal intensity) with high confidence and could be used for nodal staging. There is plenty of space to develop this idea in future prospective multicentre cohort studies.

Nevertheless, the length of hospital stay with the majority of open rectal resections was shorter by 2 days in 2015, yet still rather long ( 8 days). In their systematic review and meta-analysis, Martínez-Pérez et al. [24] found that hospital stay was 1.71 days shorter in the laparoscopic group, while median hospital stay of open surgery ranges from 7 to 8 days. Besides from laparoscopy, the implementation of an effective ERAS (Enhanced Recovery After Surgery) program [25] is another option for reducing hospital stay.

The main weakness of this research is the retrospective nature of inclusion into the database as well as it being a single-centre cohort study. For completeness, 5-year OS data are required in the future. Besides, it is worth adding all population cancers without removing transanal endoscopic microsurgery and palliative operations.

The other limitation of the study pertains to the radiological staging perspective which is due to the retrospective data collection as well as the absence of a united pelvic MRI evaluation form. As a result of this study, our centre established a standard pelvic MRI evaluation form for RC.

It is suggested that all patients with RC should undergo a detailed examination process as a compulsory routine, which should afterwards be discussed at multidisciplinary tumour boards. A standard proforma for MRI and pathology ensures a comprehensive report which leads to a more precise preoperative and operative treatment strategy.

\section{Conclusions}

The expanded quantity of preoperative imaging, an improved radiological staging, and compulsory MDT board discussion have led to a selective NT decision followed by surgery which can positively affect the 2 -year OS rate. 


\section{Statement of Ethics}

The study protocol was approved by the Bioethics Centre of LUHS (approval number BEC-MF-790).

\section{Disclosure Statement}

The authors have no conflicts of interest to declare.

\section{References}

1 International Agency for Research on Cancer (IARC). GLOBOCAN 2018 [cited 12th September, 2018]. Available from: www.globocan.iarc.fr/.

2 Center MM, Jemal A, Ward E. International trends in colorectal cancer incidence rates. Cancer Epidemiol Biomarkers Prev. 2009 Jun; 18(6):1688-94.

3 ECIS - European Cancer Information System. 2018 [cited 13th July, 2018]. Available from https://ecis.jrc.ec.europa.eu/index.php.

4 Allemani C, Matsuda T, Di Carlo V, Harewood R, Matz M, Nikšić M, et al.; CONCORD Working Group. Global surveillance of trends in cancer survival 2000-14 (CONCORD-3) analysis of individual records for 37513025 patients diagnosed with one of 18 cancers from 322 population-based registries in 71 countries. Lancet. 2018 Mar;391(10125): 1023-75.

5 Poskus E, Kryzauskas M, Poskus T, Mikalauskas S, Samalavicius NE, Aliosin O, et al. Improved perioperative care is associated with improved long-term survival in colorectal cancer. Int J Colorectal Dis. 2018 Jun;33(6): 779-85.

6 Samalavičius N, Aleknavičius E, Pilieskienė A (2014). Tiesiosios žarnos vèžio diagnostika ir gydymas. Sam.lrv.lt. [cited 9th July, 2018]. Available from: https://sam.lrv.lt/diagnostikos-gydymo-metodikos-ir-rekomendacijos/diagnostikos-ir-gydymo-protokolai.

7 Berho M, Narang R, Van Koughnett JA, Wexner SD. Modern multidisciplinary perioperative management of rectal cancer. JAMA Surg. 2015 Mar;150(3):260-6.

8 Latkauskas T, Pauzas H, Kairevice L, Petrauskas A, Saladzinskas Z, Janciauskiene R, et al. Preoperative conventional chemoradiotherapy versus short-course radiotherapy with delayed surgery for rectal cancer: results of a randomized controlled trial. BMC Cancer. 2016 Dec;16(1):927.

9 Bochis OV, Fekete Z, Vlad C, Fetica B, Leucuta DC, Busuioc CI, et al. The importance of a multidisciplinary team in rectal cancer management. Clujul Med. 2017;90(3):279-85.
10 van der Paardt MP, Zagers MB, Beets-Tan RG, Stoker J, Bipat S. Patients who undergo preoperative chemoradiotherapy for locally advanced rectal cancer restaged by using diagnostic MR imaging: a systematic review and meta-analysis. Radiology. 2013 Oct;269(1): 101-12.

11 Beets-Tan RG, Lambregts DM, Maas M, Bipat S, Barbaro B, Caseiro-Alves F, et al. Magnetic resonance imaging for the clinical management of rectal cancer patients: recommendations from the 2012 European Society of Gastrointestinal and Abdominal Radiology (ESGAR) consensus meeting. Eur Radiol. 2013 Sep;23(9):2522-31.

12 Dindo D, Demartines N, Clavien PA. Classification of surgical complications: a new proposal with evaluation in a cohort of $6336 \mathrm{pa}-$ tients and results of a survey. Ann Surg. 2004 Aug;240(2):205-13.

13 Clavien PA, Barkun J, de Oliveira ML, Vauthey JN, Dindo D, Schulick RD, et al. The Clavien-Dindo classification of surgical complications: five-year experience. Ann Surg. 2009 Aug;250(2):187-96.

14 Benitez Majano S, Di Girolamo C, Rachet B, Maringe C, Guren MG, Glimelius B, et al. Surgical treatment and survival from colorectal cancer in Denmark, England, Norway, and Sweden: a population-based study. Lancet Oncol. 2019 Jan;20(1):74-87.

15 Yimei J, Ren Z, Lu X, Huan Z. A comparison between the reference values of MRI and EUS and their usefulness to surgeons in rectal cancer. Eur Rev Med Pharmacol Sci. 2012 Dec; 16(15):2069-77.

16 Balyasnikova S, Brown G. Imaging advances in colorectal cancer. Curr Colorectal Cancer Rep. 2016;12(3):162-9.

17 Prades J, Remue E, van Hoof E, Borras JM. Is it worth reorganising cancer services on the basis of multidisciplinary teams (MDTs)? A systematic review of the objectives and organisation of MDTs and their impact on patient outcomes. Health Policy. 2015 Apr;119(4): 464-74.

18 Keller DS, Wexner SD, Chand M. Multidisciplinary Rectal Cancer Care in the United States: Lessons Learned from the United Kingdom Multidisciplinary Team Model and Future Perspectives. Dis Colon Rectum. 2018 Jul;61(7):753-4.
19 Sauer R, Becker H, Hohenberger W, Rödel C, Wittekind C, Fietkau R, et al.; German Rectal Cancer Study Group. Preoperative versus postoperative chemoradiotherapy for rectal cancer. N Engl J Med. 2004 Oct;351(17): 1731-40.

20 Kairevičè L, Latkauskas T, Tamelis A, Petrauskas A, Paužas H, Žvirblis T, et al. Preoperative long-course chemoradiotherapy plus adjuvant chemotherapy versus short-course radiotherapy without adjuvant chemotherapy both with delayed surgery for stage II-III resectable rectal cancer: 5-Year survival data of a randomized controlled trial. Medicina (Kaunas). 2017;53(3):150-8.

21 Glynne-Jones R, Wyrwicz L, Tiret E, Brown G, Rödel C, Cervantes A, Arnold D. Rectal cancer: ESMO Clinical Practice Guidelines for diagnosis, treatment and follow-up. Ann Oncol. 2017 Jul 1;28(suppl_4):iv22-40.

22 Brown G, Richards CJ, Bourne MW, Newcombe RG, Radcliffe AG, Dallimore NS, et al. Morphologic predictors of lymph node status in rectal cancer with use of high-spatialresolution MR imaging with histopathologic comparison. Radiology. 2003 May;227(2): 371-7.

23 Zhang H, Zhang C, Zheng Z, Ye F, Liu Y, Zou $S$, et al. Chemical shift effect predicting lymph node status in rectal cancer using highresolution MR imaging with node-for-node matched histopathological validation. Eur Radiol. 2017 Sep;27(9):3845-55.

24 Martínez-Pérez A, Carra MC, Brunetti F, de'Angelis N. Short-term clinical outcomes of laparoscopic vs open rectal excision for rectal cancer: A systematic review and meta-analysis. World J Gastroenterol. 2017 Nov;23(44): 7906-16.

25 Gustafsson UO, Scott MJ, Hubner M, Nygren J, Demartines N, Francis N, et al. Guidelines for Perioperative Care in Elective Colorectal Surgery: Enhanced Recovery After Surgery $\left(\right.$ ERAS $\left.^{\circledR}\right)$ Society Recommendations: 2018. World J Surg. 2019 Mar;43(3):659-95. 